\title{
ADEQUAÇÃO DE PEQUENOS MUNICÍPIOS AS EXIGÊNCIAS DA POLÍTICA NACIONAL DE RESÍDUOS SÓLIDOS: ESTUDO DE CASO NOS MUNICÍPIOS DE VIÇOSA-MG E SEUS LIMÍTROFES
} Adequacy of small municipalities to the requirements of national solid waste policy: the case of viçosa-mg and its bordering Adecuación de los pequeños municipios a las exigencias de la política nacional de residuos sólidos: el caso de viçosa-mg y sus vecinos

ELTON ROGÉRIO
GONÇALVES
BARBOSA
Universidade
Federal de Viçosa
GISLAINE
APARECIDA
SANTANA
SEDIYAMA
Universidade
Federal de Viçosa
ANDERSON DE
OLIVEIRA REIS
Universidade
Federal de Juiz de
Fora
LAYON CARLOS
CEZAR
Universidade
Federal de Alfenas
Submetido em
09.01.2016.
Aprovado em
31.10.2016
Avaliado pelo
processo de
double blind
review.

review.

\section{RESUMO}

Objetivou-se com este estudo compreender como as adequações da Política Nacional de Resíduos Sólidos (PNRS) têm sido realizadas pelo município de Viçosa e seus limítrofes. Esta pesquisa justifica-se frente às dificuldades dos municípios em se adequarem as exigências da lei tornando necessário assim, entender os reais motivos que justificam tal dificuldade. Para efetivação desse estudo, os dados foram coletados por meio de questionários aplicados aos responsáveis pela gestão dos resíduos sólidos nos respectivos municípios, pela consulta aos dados dos Planos Plurianuais de cada um dos municípios e a comparação desses às exigências da PNRS. Os principais resultados sinalizam que apesar do conjunto de dados serem em sua maioria de ações positivas quanto à gestão dos resíduos sólidos, algumas medidas evidenciam que não se pode afirmar total adaptabilidade dos municípios às exigências da PNRS.

Palavras-chave: Resíduo Sólido. Gestão Municipal. Gestão Integrada.

\section{Abstract}

This study aimed to understand how the adequacies of the National Policy of Solid Waste (PNRS) have been conducted in Viçosa and its neighbors. This research is justified front of difficulties of municipal managers to adjust the solid waste management to the requirements of the law making it necessary to understand the real reasons for this difficulty. For realization of this study, data were collected through questionnaires given to those responsible for solid waste management in their municipalities by the query to the data of the Multi-Year Plans of each of these and to compare these with the requirements of PNRS. The main results indicate that despite the set of data is mostly positive actions regarding the management of solid waste, some measurements show that one can not claim complete adaptability to the demands of the municipalities PNRS.

Keywords: Solid Waste. Municipal management. Integrated management.

\section{Resumen}

El objetivo del estudio fue comprender cómo los ajustes de la Política Nacional de Residuos Sólidos (PNRS)- hayan sido realizado en Viçosa y sus vecinos. Esta investigación se justifica en vista de las dificultades de los gestores municipales en juego de gestión de residuos sólidos a los requisitos de la ley, comprendiendo las verdaderas razones de esta dificultad. Para la realización de este estudio, los datos fueron recogidos a través de cuestionarios dados a los responsables de la gestión de residuos sólidos en sus respectivos municipios, por la consulta a los datos de los "Planos Plurianuais" de cada uno de ellos y comparar estos con los requisitos de la PNRS. Los principales resultados indican que a pesar de la serie de datos es en su mayoría de acciones positivas con respecto a la gestión de los residuos sólidos, algunas mediciones muestran que no se puede reclamar la adaptación completa de los municipios a las demandas de la PNRS.

Palabras Claves: Residuo sólido. Gestión municipal. Gestión Integrada 


\section{INTRODUÇÃO}

Os resíduos sólidos surgem a partir das atividades humanas por meio da utilização de produtos no cotidiano, sendo que $98 \%$ deles são originados das indústrias (FREIRE, 2009). A geração de resíduos sólidos além de consumir os recursos naturais, contamina a água, o solo e o ar, fato que gera graves problemas ambientais a partir da dificuldade da disposição final desses resíduos (MILLER JR, 2008). Tal problema teve destaque a partir de 1960, em vários países da Europa ocidental, devido ao aumento na quantidade de resíduos produzidos e à falta de locais específicos para correta disposição (BROLLO, 2001).

Muitos países realizam ações por meio da criação de legislações específicas que contribuam para o controle e a redução da geração destes materiais e seu correto descarte final em locais apropriados (KAWAICHI; MIRANDA, 2008). No Brasil, a abordagem legal da matéria ambiental e da sustentabilidade remonta há mais de trinta anos. É referenciada pela lei n. 6.938 de 31 de agosto de 1981, que dispõe sobre a Política Nacional do Meio Ambiente (VARELLA, 2011; REVEILLEAU, 2011, SILVA FILHO; SOLER, 2012; GUARNIERI et al., 2013), os fins tratados pela Lei, os mecanismos de formulação e aplicação e pela Constituição Federal em 1988. Todavia, a lacuna de uma legislação específica que regulamentasse a questão dos resíduos sólidos só foi resolvida a partir de 2010, com a criação da Lei no 12.305/10, intitulada Política Nacional de Resíduos Sólidos (PNRS), regulamentada pelo Decreto no 7404/10 (MMA, 2013).

A PNRS (BRASIL, 2010a) discorre sobre a questão dos resíduos sólidos trazendo instrumentos, diretrizes e normas relativas à questão dos planos nacional, estaduais, microrregionais, intermunicipais, municipais e os planos de gerenciamento de resíduos sólidos industriais. Entre suas principais propostas estão as prioridades na gestão do resíduo, como a não geração, redução, reutilização, reciclagem, tratamento e disposição adequada, e a extinção dos lixões em todos os municípios brasileiros até agosto de 2014 (BRASIL, 2010a). Além disso, possibilita o consorciamento entre municípios vizinhos para a gestão dos resíduos sólidos.

De acordo com Demajorovic e Migliano (2013), pode-se afirmar que há uma contradição de visões quando se centra a discussão sobre gestão integrada. Segundo o autor, essa visão sugere uma limitação ao enfatizar os aspectos técnicos com coleta, destinação final e transporte. Jacobi e Besen (2011) destacam que essa vertente centra-se em conjunto articulado de ações (normativas, operacionais e financeiras; de planejamento; administrativas; sociais; de monitoramento, supervisão e avaliação) que comporia a administração dos resíduos sólidos, desde a sua geração até a sua disposição final, a fim de obter benefícios ambientais, otimização econômica e aceitação social.

Nesse sentido, a lei inova ao enfatizar o sistema de logística reversa, no qual o gerador é responsável pelo destino final de seu produto pós-consumo. Tendo, deste modo, a coleta seletiva como mecanismo de apoio e incentivo a empreendimentos de catadores nas ações que envolvam fluxo de resíduos sólidos.

Em seu Art. 54으, a PNRS (BRASIL, 2010a), estabelece prazos para a implantação de acordos setoriais entre todos os atores envolvidos na gestão dos resíduos sólidos, assim como define o horizonte de quatro anos para a implantação de aterros sanitários e a eliminação de aterros controlados e lixões. No entanto, o que se verifica é a não adequação de grande parte dos municípios brasileiros às exigências da lei por inúmeros motivos como a falta de informações, falta de capacidade técnica, falhas no processo de comunicação, dentre outros motivos (CEZAR, 2014). Assim, esta pesquisa se justifica na medida em que procurou 
compreender como o município de Viçosa-MG e seus respectivos municípios limítrofes têm se adequado às exigências da PNRS. Especificamente pretende-se (i) verificar as ações empreendidas por cada município em relação a temática dos resíduos sólidos; (ii) identificar o modelo de planejamento municipal descrito no Plano Plurianual (PPA) de cada município para a gestão destes materiais e (iii) verificar a aderência do planejamento municipal às exigências da PNRS.

A partir da presente investigação pretende-se reunir elementos que evidenciem a realidade vivenciada em Viçosa-MG e região, buscando assim trazer à luz elementos que possam ser partilhados entre municípios de outras regiões brasileiras, mas com características semelhantes. Além disso, o estudo visa tentar compreender como municípios de pequeno porte, que geralmente apresentam fragilidade em termos de gestão pública, estão agindo frente à necessidade de adequação à PNRS e o quanto já avançaram em direção ao cumprimento da lei.

\section{Fundamentação Teórica}

Este tópico está dividido em duas seções e servira de base para a análise e discussão dos resultados. Na primeira seção elabora-se uma revisão sistemática da origem das Políticas de Gerenciamento de Resíduos Sólidos. Já na segunda parte trata-se exclusivamente da forma como se consolidou a Política Nacional de Resíduos Sólidos em vigor atualmente.

\subsection{PRIMÓRDIOS DAS POLÍTICAS NACIONAIS E ESTADUAL DE GERENCIAMENTO DE RESÍDUOS SÓLIDOS NO BRASIL}

O surgimento da legislação ambiental brasileira inicia-se a partir de 1930, quando o estado brasileiro assume realmente a função de regulador e articulador desta, de forma a disciplinar a correta utilização e a proteção dos recursos naturais brasileiros (SILVA-SÁNCHEZ, 1999).

No intervalo de cinco décadas, o Brasil passou de uma posição retrógada, adotada na primeira conferência do clima em Estocolmo, na Suécia em 1972, na qual se posicionou contrariamente à redução dos níveis de poluição a anfitrião da Conferência das Nações Unidas sobre o Meio Ambiente e o Desenvolvimento, também conhecida como Eco 92 e da conferência ocorrida 20 anos depois, a Rio +20 . Ambas as conferência sendo realizadas na cidade do Rio de Janeiro, para uma posição de ação planejada; o que demonstra uma mudança de posicionamento do Brasil mesmo que timidamente, com relação às questões ambientais (GUIMARÃES; FONTOURA, 2012).

O marco regulatório importante na legislação brasileira com relação ao assunto aconteceu em 1981 com a criação da Política Nacional do Meio Ambiente e do Instituto Brasileiro do Meio Ambiente e dos Recursos Naturais Renováveis (IBAMA). A Constituição Federal de 1988 deu um destaque especial à questão ambiental em seu art. 225, garantindo a todos os cidadãos acesso ao meio ambiente utilizando-o de forma racional e equilibrada, além de ser obrigação do poder público e da coletividade protegê-lo para as atuais e futuras gerações.

O Ministério do Meio Ambiente passou a ter a missão de formular a Política Nacional de Meio Ambiente a partir do ano de 1992 (MMA, 2013). Além disto, foram criadas várias leis sobre a temática ambiental entre elas: a Lei de Crimes Ambientais (Lei $n^{\circ}$ 9.605/98), o Sistema 
Nacional de Unidades de Conservação (SNUC)( Lei $n^{\circ}$ 9.985/00), a Lei da Tutela da Água no Brasil (Lei $n^{\circ}$ 9.433/97), que instituiu a Política Nacional de Recursos Hídricos (PNRH) e a Lei ${ }^{\circ}$ 9.984/00, que criou a Agência Nacional das Águas (ANA) (BORGES; REZENDE; PEREIRA,2009).

No ano de 2007 foi criada a Lei no 11.445/07 que estabeleceu diretrizes nacionais para - Saneamento Básico, intitulada de lei do saneamento básico, que trouxe importantes avanços, como: a universalização do Saneamento Básico e a implantação do Plano Nacional, Estadual e Municipal de Saneamento Básico a serem realizados pelos entes da Administração Pública (CORDEIRO, 2009).

Como crítica a essa lei, Hohmann (2012, p.217) considera que ela “(...) não respondeu uma das questões centrais e urgentes referentes à prestação dos serviços de saneamento, que seria a sua titularidade". Outra questão pertinente foi que a lei não contemplou questões referentes aos resíduos sólidos em seu conteúdo, sendo esta lacuna coberta no ano de 2010 com o surgimento da Política Nacional de Resíduos Sólidos (PNRS) a partir da Lei 12305/10. Já outros autores, entre eles Souza (2009), que relata sobre o atraso do desenvolvimento da política ambiental brasileira comparada com as outras políticas setoriais do país ocorreu em função das pressões externas dos países desenvolvidos.

De acordo com Cezar (2014), inúmeras políticas, medidas e ações foram criadas para tentar estimular a necessidade de uma política orientada de fato para a questão dos resíduos sólidos. Políticas como a Política Nacional de Meio Ambiente e a Política Nacional de Saneamento Básico foram necessárias, mas não suficientes para dar o devido rigor à questão do "lixo". Sendo assim, o autor destaca o cenário perfeito para o surgimento da Política Nacional de Resíduos Sólidos em 2010.

Além das políticas nacionais, observam-se esforços em âmbito estadual para a melhoria das questões ambientais. No estado de Minas Gerais, em 2003, foi lançado o programa "Minas sem Lixões", criado pela Fundação Estadual do Meio Ambiente (FEAM). O intuito desse programa era apoiar os municípios mineiros na implementação de políticas públicas ambientais voltadas para uma correta gestão dos Resíduos Sólidos urbanos, tendo como objetivo principal a extinção dos lixões a céu aberto em todos os municípios mineiros (FEAM, 2013). No estado de São Paulo, foi promulgada a Lei 12.300, de 16 de março de 2006, a fim de possibilitar a inserção de catadores, associações e cooperativas no processo de coleta, separação e comercialização dos resíduos sólidos urbanos (GUTIERREZ; ZANIN, 2011).

Os Resíduos Sólidos urbanos têm como principal destinação final os lixões, Aterros Controlados e em menor escala os Aterros Sanitários e as Usinas de Triagem e Compostagem (UTC) (FREIRE, 2009). Os lixões são conceituados por Carvalho e Lanza (2006, p. 8) como “(...) uma forma inadequada de disposição final de resíduos sólidos, caracterizada pela sua descarga sobre o solo, sem critérios técnicos e medidas de proteção ambiental ou à saúde pública. É o mesmo que descarga a "céu aberto'". As Usinas de Triagem e Compostagem (UTC) são os locais onde ocorre a separação dos materiais recicláveis, orgânicos, dejetos e resíduos especiais por meio da utilização de equipamentos e de pessoal qualificado para realização dos procedimentos. Cada um desses materiais que entra na UTC tem um destino especifico (CARVALHO; LANZA, 2006).

Outra forma de disposição final dos resíduos sólidos representada pelos empreendimentos ou atividades consideradas de impacto ambiental não significativo estão dispensados do licenciamento ambiental e devem, obrigatoriamente, requerer a Autorização Ambiental de Funcionamento (AAF), um processo mais simples e rápido para a regularização (MINAS GERAIS, 2014). 


\subsection{CONSOLIDAÇÃO DA POLÍTICA NACIONAL DE RESÍDUOS SÓLIDOS (PNRS)}

A problemática sobre os Resíduos Sólidos ganhou ainda mais destaque em vários países do mundo, principalmente, a partir de 1990, quando estes enfrentavam sérios problemas com relação aos altos custos de recolhimento e de reciclagem, além da falta de locais adequados para a disposição final destes resíduos. Estas nações foram responsáveis pela incorporação do tema Resíduos Sólidos, na pauta de assuntos do Eco 92, refletindo no Brasil o início das discussões sobre uma política pública nacional específica para o setor (MILANEZ; BÜHRS, 2009).

No ano de 2004, iniciaram-se as discussões no Congresso Nacional para a criação de uma política que disciplinasse a questão dos Resíduos Sólidos no país, com a participação do Conselho Nacional do Meio Ambiente (CONAMA), Fundação Nacional da Saúde (FUNASA), Caixa Econômica Federal e os Ministérios do Meio Ambiente, das Cidades e da Saúde e representantes da sociedade civil. Após a realização de várias audiências públicas, visitas, debates e reuniões técnicas externas foi aprovada, em 02 de agosto de 2010, a Lei no 12.305/10 que institui a política nacional de resíduos sólidos (a qual foi regulamentada pelo decreto no 7404/10, com a entrada em vigor a partir de 2011 (BRASIL, 2010a; 2010b). Esta Lei apresentava como prazo final para adequação às exigências nela contida, o mês de agosto de 2014 (MMA, 2013).

A Lei de Resíduos Sólidos (LRS) estabelece os objetivos e as diretrizes nacionais para os resíduos sólidos com a criação do Comitê Interministerial da PNRS dos planos nacionais, estaduais, distrital, intermunicipais, municipais e os planos de gerenciamento de resíduos sólidos industriais. A Lei trata de forma clara e objetiva a questão da correta gestão dos resíduos; prevê a responsabilidade compartilhada entre todos que fazem parte do ciclo de vida dos produtos, que se inicia desde os fabricantes até os consumidores finais e os responsáveis pela limpeza urbana (JULIATTO; CALVO; CARSOSO, 2011).

No âmbito municipal, a PNRS determina que todos os municípios brasileiros com população superior a 20.000 habitantes estão obrigados a elaborar os seus Planos Municipais de Gestão Integrada de Resíduos Sólidos (PMGIRS) que devem conter $19^{1}$ itens básicos para que o município esteja de acordo com a legislação atual. Já no caso dos municípios com população inferior a 20.000 habitantes a legislação possibilita a elaboração do Plano Municipal de Gestão de Resíduos Sólidos em sua versão simplificada (PSGIRS) que contém $14^{2}$ itens básicos a serem contemplados pelos municípios (BRASIL, 2010a; 2010b).

A Lei prevê, ainda, o planejamento a médio e em longo prazo, com a incorporação do tema no PPA (Plano Plurianual). Assim, os entes da Administração Pública podem conceder

\footnotetext{
${ }^{1}$ Os 19 itens a serem contemplados pelo PMGIRS tratam de diversos assuntos correlacionados a temática dos resíduos sólidos entre eles: diagnóstico dos resíduos sólidos gerados nos respectivos territórios bem como uma correta gestão em se tratando de sua disposição final, implantação de soluções consorciadas entre os entes da federação e os municípios com relação à disposição final destes materiais. Educação ambiental para incentivar a não geração, redução e a reutilização destes materiais. Desenvolver parcerias entre o poder público e entidades que atuam neste setor capacitando os seus funcionários destas organizações a atuarem no ramo da coleta, tornando este procedimento mais prático e objetivo. Periocidade do PMGIRS e a sua revisão observando a vigência do PPA do respectivo munícipio.

${ }^{2}$ O PSGIRS contém 14 itens basicamente, englobando as questões mais importantes relatadas no PMGIRS, diferenciando basicamente na possibilidade de ter o seu conteúdo mais resumido devido a sua aplicação ocorrer em municípios com população inferior a 20.000 mil habitantes,
} 
incentivos creditícios para atender às necessidades de fomento da Lei desde que respeitem os limites estabelecidos pela Lei Complementar $n^{\circ}$ 101/2000. Destaca- se que a criação de consórcios regionais ou intermunicipais de resíduos sólidos tem sido incentivada pela PNRS, com a possibilidade de recebimento de incentivos financeiros e treinamento de pessoal especializado para a gestão destes empreendimentos (BRASIL, 2010a).

Ferreira e Rosolen (2012) afirmam que para que a PNRS seja realmente efetiva é necessária a participação conjunta dos três entes da Administração Pública, em conjunto com diversos setores da sociedade civil, com destaque especial para as relações comerciais entre empresas e consumidores, além da participação das associações de catadores de materiais recicláveis e reutilizáveis; o que tornaria a logística reversa realmente efetiva e possibilitaria a criação dos Arranjos Produtivos Locais capazes de gerar receitas e garantir a preservação dos recursos naturais (FERREIRA; ROSOLEN, 2012).

\section{PROCEDIMENTOS METODOLÓGICOS}

O presente estudo pode ser classificado como quantitativo e qualitativo devido sua dupla natureza de investigação. O seu caráter quantitativo pode ser justificado uma vez que para coleta de dados utilizou-se de questionário estruturado com questões a serem respondidas a partir de escalas. $\mathrm{O}$ viés qualitativo justifica-se uma vez que neste mesmo questionário foram disponibilizadas questões abertas. Em relação aos objetivos, a pesquisa pode ser classificada como exploratória e descritiva uma vez que além de descrever as percepções dos entrevistados, buscou-se promover discussões e maior familiaridade com o tema de investigação (GIL, 2010).

Em relação aos meios de coleta de dados, a pesquisa pode ser classificada como documental por utilizar os Planos Plurianuais como fonte de análise e de campo devido à necessidade de realizar entrevistas pessoais com os gestores dos municípios que atuam diretamente com a Gestão dos Resíduos Sólidos. Cabe ressaltar ainda que a pesquisa é classificada como um estudo múltiplo de caso

Os sujeitos dessa pesquisa foram representantes das Prefeituras, tais como Secretários do Meio Ambiente e/ou os assessores deles, e gestores das autarquias responsáveis pela gestão de resíduos, como é o caso da cidade de Viçosa que possui o Sistema Autônomo de Água e Esgoto (SAAE).

Para a coleta de dados foi elaborado um survey com questões fechadas e um roteiro de entrevista realizada in loco. Para Cooper; Schindler (2003) o survey permite a auto seleção dos entrevistados cedendo assim mais tempo para elaboração da resposta. Os autores destacam ainda que a utilização do survey permite a identificação de pontos específicos a serem analisados e que podem ser complementados com outras técnicas de pesquisa. Assim, como a PNRS prevê a possibilidade de elaboração de dois tipos de Planos de Gestão dos Resíduos Sólidos pelos municípios, optou-se por elaborar dois tipos de questionários para avaliar o grau de importância que o gestor atribui a cada item solicitado pela PNRS de acordo com o plano que a prefeitura pretende elaborar.

Esses questionários foram elaborados em estrutura de check list com a aplicação por meio da escala do tipo Likert. Justifica-se a aplicação destas duas opções de questionários devido à obrigatoriedade de todos os municípios elaborarem os respectivos Planos Municipais de Gestão de Resíduos Sólidos. O primeiro questionário trata do PMGIRS obrigatório para os municípios com população superior a 20.000 habitantes, contém 19 afirmativas nas quais os entrevistados possuem cinco opções de respostas, a saber: Concordo Totalmente, Concordo, 
Nem Concordo e Nem Discordo, Discordo e Discordo Totalmente. O segundo questionário, contendo 14 afirmativas com as mesmas cinco opções de respostas do primeiro, discorria sobre o PSGIRS, cuja elaboração é opcional aos municípios com população inferior a 20.000 habitantes.

A análise dos dados foi feita pela comparação das informações oferecidas pelos gestores na entrevista, com as respostas oferecidas na escala do tipo Likert e no que estava descrito no PPA do município. A análise realizada de forma conjunta tem como intuito tornar mais clara e objetiva a compreensão dos resultados.

As respostas dos entrevistados foram dispostas em forma de quadros e texto para o questionário com perguntas abertas e fechadas; já para as entrevistas referentes aos PMGIRS e o PSGIRS as respostas foram dispostas apenas em texto. Isso facilita a compreensão dos dados por parte do leitor. A discussão dos dados foi realizada a partir da comparação das respostas dos questionários com os PPA's dos respectivos municípios sendo as informações do conteúdo deste documento dispostas no Quadro 1 documento e as regulamentações da PNRS.

\subsection{UNIDADES DE ANÁLISE}

Para a realização deste estudo, estabeleceram-se como unidade de análise o município de Viçosa e suas cidades limítrofes: Cajuri, Coimbra, Paula Cândido, Porto Firme, São Miguel do Anta, Guaraciaba e Teixeiras (IBGE, 2014b). Isso se justificou pelo fato da PNRS possibilitar a realização de ações conjuntas para a gestão dos Resíduos Sólidos e para o cumprimento de outras exigências desta política.

O Quadro 1 apresenta um resumo da Gestão de Resíduos Sólidos do Município de Viçosa e seus municípios limítrofes, evidenciando a situação de Viçosa e os seus limítrofes com relação à disposição final dos Resíduos Sólidos.

\section{Quadro 1:Disposição Final de Resíduos Sólidos nos Município de Viçosa e seus Limítrofes}

\begin{tabular}{|l|l|}
\hline \multicolumn{1}{|c|}{ Disposição final de Resíduos Sólidos } & \multicolumn{1}{|c|}{ Municípios } \\
\hline Lixão & Porto Firme \\
\hline Usina de Triagem e Compostagem regularizada & $\begin{array}{l}\text { Teixeiras, São Miguel Do Anta, Coimbra, } \\
\text { Guaraciaba }\end{array}$ \\
\hline Aterro Controlado & Viçosa, Cajuri \\
\hline AAF em verificação & Paula Cândido \\
\hline
\end{tabular}

Fonte: Minas Sem Lixões, 2012

Dos oito municípios analisados, quatro possuem Usina de Triagem e Compostagem regularizada, dois possuem Aterro Controlado e um possui Autorização Ambiental de Funcionamento (AFF) em verificação e um utiliza lixão.

\section{RESULTADOS}

Os Quadros 2 e 3 dispõem, respectivamente das ações descritas no conteúdo dos PPA's dos respectivos municípios e sobre as repostas padronizadas dos entrevistados ao questionário com perguntas Abertas e Fechadas. 


\begin{tabular}{|c|c|c|c|}
\hline \multicolumn{2}{|c|}{ Municípios } & \multicolumn{2}{|c|}{ Ações Descritas no PPA 2014-2017 } \\
\hline $\begin{array}{l}\text { São Miguel } \\
\text { do Anta }\end{array}$ & $\begin{array}{l}\text { Manutenção das Atividades da } \\
\text { usina de reciclagem de lixo }\end{array}$ & $\begin{array}{l}\text { Manutenção do Serviço } \\
\text { limpeza pública }\end{array}$ & $\begin{array}{l}\text { Construção de } \\
\text { Aterro Sanitário }\end{array}$ \\
\hline $\begin{array}{l}\text { Paula } \\
\text { Cândido }\end{array}$ & $\begin{array}{l}\text { Manutenção da Usina de } \\
\text { Triagem e Compostagem de Lixo }\end{array}$ & 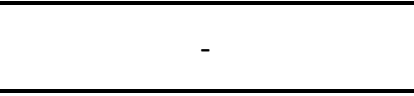 & - \\
\hline Coimbra & $\begin{array}{l}\text { Construção, Ampliação e } \\
\text { desenvolvimento da Usina de } \\
\text { Reciclagem de Lixo }\end{array}$ & $\begin{array}{c}\text { Manutenção dos serviços } \\
\text { de Limpeza Pública e coleta } \\
\text { de lixo }\end{array}$ & - \\
\hline Guaraciaba & Manutenção da Usina de Lixo & & - \\
\hline Teixeiras & $\begin{array}{l}\text { Ampliação, } \quad \text { Reforma } \\
\text { equipamento para a Usina de } \\
\text { Lixo }\end{array}$ & $\begin{array}{c}\text { Manutenção de atividade } \\
\text { de limpeza pública e da } \\
\text { Usina de lixo }\end{array}$ & - \\
\hline Cajuri & $\begin{array}{l}\text { Construção da Usina de } \\
\text { beneficiamento de lixo }\end{array}$ & $\begin{array}{c}\text { Manutenção da limpeza } \\
\text { pública }\end{array}$ & - \\
\hline Porto Firme & $\begin{array}{l}\text { Construção da Usina de Triagem } \\
\text { e Compostagem de Lixo }\end{array}$ & $\begin{array}{c}\text { Manutenção do Serviço } \\
\text { limpeza publica }\end{array}$ & - \\
\hline Viçosa & $\begin{array}{l}\text { Construção dos centros de } \\
\text { tratamento de resíduos sólidos }\end{array}$ & $\begin{array}{l}\text { Manter e ampliar o serviço } \\
\text { de limpeza, coleta e } \\
\text { destinação dos Resíduos } \\
\text { Sólidos }\end{array}$ & - \\
\hline
\end{tabular}

Quadro 2: Ações sobre Resíduos Sólidos descritas nos PPA's dos Municípios

Fonte: Dados da Pesquisa, 2014. 
Quadro 3: Respostas dos entrevistados

\begin{tabular}{|c|c|c|c|c|c|c|c|c|}
\hline Questões/Municípios & Viçosa & Teixeiras & Guaraciaba & Porto Firme & Paula Cândido & Coimbra & $\begin{array}{l}\text { São Miguel } \\
\text { Do Anta }\end{array}$ & Cajuri \\
\hline $\begin{array}{l}\text { Órgão responsável pela } \\
\text { limpeza urbana }\end{array}$ & SAAE & Prefeitura & Prefeitura & Prefeitura & Prefeitura & Prefeitura & Prefeitura & Prefeitura \\
\hline $\begin{array}{l}\text { Existência da coleta } \\
\text { seletiva no Município }\end{array}$ & Sim & SIM & Não & Não & Não & Não & Não & Não \\
\hline $\begin{array}{l}\text { Existência de cooperativas } \\
\text { de catadores de materiais } \\
\text { recicláveis }\end{array}$ & Sim & Não & Não & Não & Não & Não & Não & Não \\
\hline $\begin{array}{l}\text { Destinação final dos } \\
\text { Resíduos Sólidos }\end{array}$ & $\begin{array}{l}\text { Aterro Sanitário } \\
\text { Regulamentado }\end{array}$ & UTC & UTC & $\begin{array}{l}\text { Aterro Sanitário } \\
\text { Regulamentado }\end{array}$ & $\begin{array}{l}\text { Aterro Sanitário } \\
\text { Regulamentado }\end{array}$ & UTC & UTC & $\begin{array}{l}\text { Aterro Sanitário } \\
\text { Regulamentado }\end{array}$ \\
\hline $\begin{array}{ll}\text { Participação } & \text { em } \\
\text { Consórcios } & \\
\text { Intermunicipais } & \end{array}$ & Não & Não & Não & Não & Não & Não & Sim & Não \\
\hline $\begin{array}{lll}\text { Existência } & \text { de } & \text { Lixão } \\
\text { Desativado } & & \\
\end{array}$ & Sim & Sim & Sim & Sim & Sim & Não & Sim & Sim \\
\hline $\begin{array}{l}\text { Existência no PPA de } \\
\text { ações sobre a temática } \\
\text { dos Resíduos Sólidos }\end{array}$ & Sim & Sim & Sim & Sim & Sim & Não & Sim & Não \\
\hline $\begin{array}{lcr}\text { Existência } & \text { do } & \text { Plano } \\
\text { Municipal } & \text { de } & \text { Gestão } \\
\text { Integrada } & \text { de } & \text { Resíduos } \\
\text { Sólidos } & & \end{array}$ & PMGIRS & PSGIRS & PMGIRS & PSGIRS & PGIRS & PSGIRS & Não Elaborou & PSGIRS \\
\hline
\end{tabular}

Fonte: Dados da Pesquisa, 2014. 


\subsection{ANÁLISE DOS RESULTADOS ${ }^{3}$}

Ao se questionar sobre o órgão responsável pela limpeza urbana nos municípios, os gestores municipais destacaram ser responsabilidade da prefeitura municipal. Apenas a cidade de Viçosa tem esse serviço sob responsabilidade de uma autarquia.

O Serviço Autônomo de Água e Esgoto (SAAE) é o órgão responsável pela Gestão de Resíduos Sólidos no município de Viçosa. A Diretoria deste órgão apresenta profissionais qualificados e devidamente treinados, sendo o responsável geral, pesquisador da Universidade Federal de Viçosa (UFV) na área de resíduos sólidos. O SAAE orienta vários Municípios vizinhos da cidade de Viçosa em projetos de construção de UTC's, dentre eles estão Coimbra, São Miguel do Anta, Teixeiras e Guaraciaba, bem como, auxilia este último município na elaboração do respectivo PMGIRS.

Com relação à questão da existência da coleta seletiva dos oito municípios pesquisados, apenas Viçosa e Teixeiras realizam tal ação, o que demonstra uma lacuna quanto ao atendimento aos requisitos preconizados pela legislação por parte dos outros seis municípios.

Sobre a existência de cooperativas de catadores de materiais recicláveis nos municípios pesquisados esta ação ocorre apenas no município de Viçosa a partir da Associação de Catadores de Materiais Recicláveis (ACAT) e da Associação de Catadores de Materiais Recicláveis de Viçosa (ACAMARE). De acordo com a PNRS, a realização da coleta seletiva por meio de procedimentos adequados é de responsabilidade dos titulares do serviço de limpeza urbana no município. A PNRS prevê a realização de políticas públicas por parte dos titulares da limpeza urbana nos municípios, em favor das associações de catadores de materiais recicláveis e reutilizáveis. Dentre estas ações, destacam-se: a criação e o fortalecimento institucional destas associações, a capacitação profissional e a inclusão social e econômica dos seus membros.

Ressalta-se que tais ações devem ocorrer apenas quando existirem cooperativas e ou associações no município, portanto, o fato da inexistência delas não significa que o município esteja em desacordo com a legislação atual uma vez que tais medidas representam formas de priorização da reciclagem e reinserção do resíduo à cadeia produtiva. Por outro lado, tal medida contribui com a geração de trabalho e renda para grande parte de trabalhadores que muitas vezes estão fora do mercado formal de trabalho.

Com relação à disposição final dos resíduos sólidos nos municípios, cabe destacar como fator positivo a destinação final dos resíduos nos municípios de Teixeiras, Guaraciaba, São Miguel do Anta e Coimbra, uma vez que estes municípios contam com Usinas de Triagem e Compostagem (UTC). Este fato é uma das principais exigências da PNRS, já que pretende eliminar os lixões a céu aberto até o ano de 2014.

Os municípios de Porto Firme, Paula Cândido, Cajuri e Viçosa fazem a disposição final dos resíduos em um Aterro Sanitário Regulamentado. De acordo com informações levantadas nos municípios, contatou-se que a disposição final dos resíduos no município de Paula Cândido é realizada a partir de uma Autorização Ambiental de Funcionamento (AAF), enquanto em Viçosa e Cajuri é realizada em um Aterro Controlado e em Porto Firme, em um lixão.

\footnotetext{
${ }^{3}$ A análise dos resultados foi realizada a partir da padronização das respostas dos entrevistados ao questionário com perguntas abertas e fechadas (Quadro 2) conjuntamente com as informações retiradas dos PPA's de cada um dos oito municípios campo da pesquisa.
} 
Com exceção do município de Viçosa, observa-se uma possível confusão por parte dos entrevistados nas afirmações, devido à diferença entre Aterro Sanitário Regulamentado e Aterro Sanitário Controlado. Freire (2009) relata que no primeiro caso ocorre a impermeabilização do solo de forma a evitar que tanto o solo quanto o lençol freático sejam contaminados; já no segundo caso, esta ação não ocorre, sendo a destinação final apenas um grau acima de eficiência quando comparado à disposição final de resíduos sólidos em lixões.

A Fundação Estadual do Meio Ambiente (FEAM) que é o órgão estadual responsável pela fiscalização da situação dos municípios mineiros com relação à disposição final os resíduos sólidos, divulga anualmente tais dados. Assim, a análise da situação da disposição final dos resíduos nos municípios foi realizada a partir de dados relativo ao ano base de 2012 disponibilizada pela FEAM e comparada com as respostas dos entrevistados. Devido à impossibilidade de consulta dos dados referentes ao ano de 2013 do estudo da FEAM, por questões de ordem eleitoral, constatou-se uma limitação na verificação da real situação destes municípios com relação à disposição final dos resíduos sólidos nos respectivos territórios.

Com relação à participação em Consórcios Intermunicipais para a Gestão de Resíduos sólidos, verifica-se que apenas o município de São Miguel do Anta participa de um consórcio e recebe os resíduos materiais do município de Canãa. Os municípios de Porto Firme e Teixeiras apesar de não realizarem ações consorciadas, demonstraram interesse em realizálas futuramente.

Como justificativa para a não realização de consorciamento pelos municípios, foram elencados pelos gestores as questões de logística de transporte, a distância geográfica, o custo de operacionalização de uma Usinas de Triagem e Compostagem (UTC) e a falta de pessoal treinado para a realização da separação dos materiais e para a gestão da usina.

Com exceção do município de Viçosa, entende-se que os entrevistados não se embasaram em um estudo técnico para fazer as afirmações e para oferecer as justificativas para o não consorciamento, além de demostrarem um desconhecimento da PNRS, já que esta prevê a possibilidade de consorciamento entre os municípios para a disposição final dos resíduos sólidos, com facilidades para a aquisição de parcerias com outros órgãos públicos para a realização dos consórcios.

No entanto, como a PNRS não obriga a realização por parte dos municípios de ações consorciadas para a gestão dos resíduos sólidos, não se pode afirmar que eles estejam em desacordo com a legislação atual. A PNRS sugere que os consórcios auxiliem na concentração de esforços coletivos para que juntos os municípios não só compartilhem os custos inerentes na construção e manutenção da infraestrutura necessária para correta destinação dos resíduos, mas, que viabilizem alternativas para o compartilhamento de resultados.

Sobre a existência de lixão desativado nos municípios e como é realizada a gestão destes locais, constata-se que apenas o município de Coimbra não possui lixão desativado, devido ao fato de possuir uma UTC há mais de 20 anos. Nos outros municípios existem lixões desativados, para os quais, no entanto, foram realizadas medidas corretivas para evitar a contaminação do solo e consequentemente do lençol freático como; o isolamento da área por meio do plantio de árvores ou ocorreu o crescimento da vegetação nativa no local.

Sobre a existência no PPA de ações sobre a temática dos resíduos sólidos nos municípios pesquisados, os dados revelam que dos oito municípios estudados, apenas em Coimbra e Cajuri, os entrevistados afirmaram que não existem tais ações descriminadas no documento sobre a temática em estudo. 
A PNRS discorre claramente sobre a correlação entre a gestão dos resíduos sólidos e a discriminação dessa gestão no PPA, além do que os planos municipais de gestão de resíduos devem ser revisados concomitantemente com o PPA. Este fato fica evidente quando se consulta os PPA's dos municípios nos quais em todos se verificam tais ações. Tal percepção demonstra desconhecimento por parte dos entrevistados quanto ao conteúdo deste documento e da importância dele como um instrumento de planejamento e gestão para a administração pública.

Sobre a questão da elaboração do Plano Municipal de Gestão de Resíduos Sólidos nos municípios, os entrevistados salientaram que a empresa Vallenge Engenharia foi responsável pela elaboração do Plano Municipal de Saneamento Básico (PMSB) nos municípios de Cajuri, Coimbra, Paula Cândido, Teixeiras e São Miguel do Anta; além de estar em processo de elaboração do PSGIRS destes municípios, com exceção de São Miguel do Anta.

Percebe-se, a partir das afirmativas dos entrevistados, o desconhecimento dos gestores quanto à PNRS, com exceção do município de Viçosa, já que nas afirmativas transparece uma confusão sobre a elaboração, respectivamente, dos PMGIRS, PSGIRS e PMSB.

De acordo com a PNRS, tanto o PMGRS quanto o PSGIRS podem estar inseridos dentro do PMSB do município, desde que atendam às exigências legais. Com relação ao município de São Miguel do Anta é possível que a empresa Vallenge Engenharia, também, esteja elaborando-o, mas esta afirmação não pôde ser comprovada devido à impossibilidade de obtenção de uma resposta da empresa com relação a este questionamento.

De acordo com a PNRS (BRASIL, 2010a; 2010b), os titulares responsáveis pela limpeza urbana nos municípios devem elaborar os respectivos Planos Municipais de Gestão de Resíduos Sólidos (PMGRS). Assim, o fato de uma empresa privada elaborar tal documento demonstra o desconhecimento técnico por parte do setor responsável pela gestão de resíduos da administração municipal para elaborar os respectivos planos.

Os gestores do município de Guaraciaba mostraram que são os mais eficientes com relação ao cumprimento das exigências da PNRS, devido ao fato de ser o único município em que os entrevistados já haviam elaborado o PMGIRS e dispunham dele em mãos.

Com relação às respostas dos entrevistados sobre os questionários em formato check list sobre os PMGIRS, dos dois municípios que elaboraram o respectivo plano apenas no município de Guaraciaba ocorreu uma resposta adversa por parte do entrevistado respondendo "Discordo Totalmente" com relação ao item 2 que se refere à existência de ações de identificação de áreas favoráveis para disposição final ambientalmente adequada de rejeitos, observado o plano diretor. O entrevistado de Viçosa respondeu que "Concorda Totalmente" para todos os 19 itens do respectivo PMGIRS.

De acordo com a PNRS os municípios com população inferior a 10 mil habitantes tem como opção elaborar o Plano de Gerenciamento de Resíduos Sólidos em seu modelo simplificado (PSGIRS). Sendo que este plano foi elaborado em cinco municípios: Teixeiras, Paula Cândido, Porto Firme, Coimbra e Cajuri sendo que apenas no último o entrevistado respondeu adversamente a todos os 14 itens a partir da alternativa "Discordo". Como restrição a análise cabe afirmar que em nenhum dos cinco municípios foi possível verificar a existência física dos respectivos planos.

\section{CONSIDERAÇÕES FINAIS}

Este estudo teve por objetivo compreender como os municípios de Viçosa, Paula Cândido, Porto Firme, Guaraciaba, Teixeiras, Coimbra, São Miguel do Anta e Cajuri se 
adequaram às exigências da PNRS. Os dados revelaram que, apesar do conjunto de dados coletados nos municípios, obtidos a partir de afirmações dos entrevistados e na consulta realizado aos PPA's serem compostos majoritariamente de ações positivas com relação à gestão de resíduos sólidos, não se pode afirmar que os municípios cumpram integralmente as exigências da PNRS.

O desconhecimento técnico por parte dos entrevistados foi verificado durante a realização da entrevista, com exceção do município de Viçosa e Guaraciaba, em que no segundo caso foi possível verificar a existência do PMGIRS. A partir de uma consulta física, realizada no momento da entrevista, foi possível constatar a existência das ações descritas pela PNRS no conteúdo do documento em Guaraciaba.

O problema da falta de conhecimento técnico fica evidente quando os entrevistados discorrem sobre a não ocorrência de ações no município como, a realização da coleta seletiva (exceção de Teixeiras e Viçosa), a destinação final dos resíduos e a realização de consorciamento. Apenas os gestores do município de São Miguel do Anta realizam consorciamento com intuito de tornar mais eficiente a gestão dos resíduos.

Cabe ressaltar em relação ao desconhecimento sobre a temática dos resíduos sólidos nos PPA's que os entrevistados de Coimbra e Cajuri demonstram desconhecimento quanto à elaboração e à realização das ações descritas no PPA, sendo esse um importante documento de gestão para o longo e médio prazo na administração pública.

Ocorreu, também, por parte dos entrevistados, com exceção ao município de Viçosa, uma confusão sobre a legislação atual que disciplina a temática dos resíduos sólidos, uma vez que, no ano de 2003 foi criado pela FEAM, o programa "Minas Sem Lixões"; em 2007 surgiu a Lei do saneamento básico e, em 2010, foi criada a PNRS. Nas falas, ficou evidente o fato de os gestores não saberem quais ações se referem a cada uma das exigências das legislações citadas, o que nos permite concluir que existe um desconhecimento por parte deles das essências e da exigibilidade destas legislações.

$\mathrm{Na}$ prática, todas estas ações impostas pela legislação supracitada têm como denominador comum a extinção dos lixões a céu aberto no Brasil. A Lei do saneamento básico obriga todos os municípios a elaborarem os respectivos PMSB. Já os Planos Municipais de Gestão de Resíduos Sólidos que são uma exigência da PNRS podem ser inseridos dentro do PMSB. Portanto, percebe-se uma confusão por parte da maioria dos entrevistados destas duas ações tão importantes para a gestão dos resíduos sólidos nos municípios.

Além do mais, o fato de uma empresa privada elaborar os PSGIRS para os municípios de Paula Cândido, Coimbra, Teixeiras e Cajuri, e provavelmente do município de São Miguel do Anta, confirma a falta de capacidade técnica dos entrevistados, visto que a PNRS determina que os responsáveis pela limpeza urbana tenham que elaborar os respectivos Planos Municipais de Gestão de Resíduos Sólidos. Entende-se que a questão dos resíduos sólidos, ainda, não tem o destaque merecido por parte dos gestores, além destes não se beneficiarem das vantagens oferecidas pela PNRS para que ocorra uma correta gestão dos resíduos nos respectivos territórios. Ressalta-se ainda a importância de convocar a sociedade civil para a participação nas esferas institucionais de diálogo para que os respectivos planos de gestão dos resíduos sejam os mais próximos possíveis às demandas locais e regionais dos munícipes e não como um objeto instrumental criado por empresas que desconhecem as particularidades de determinada região.

Por fim, é preciso registrar que este estudo não esgota o assunto, mas contribui ao revelar a situação individual e coletiva dos municípios pesquisados. Além de deixar possibilidades para a realização de estudos futuros, uma vez que, a PNRS prevê ações a serem 
realizadas no horizonte de 20 anos, desde sua sanção, por parte dos gestores municipais o que permite a realização de pesquisas posteriores relativas à efetiva aplicação do programa com a implantação de políticas públicas que busquem a eficiência na gestão dos resíduos sólidos no âmbito municipal.

\section{REFERÊNCIAS}

BORGES, Luís Antônio Coimbra; REZENDE, José Luiz Pereira de; PEREIRA, José Aldo Alves. Evolução da Legislação Ambiental no Brasil. Revista em Agronegócios e Meio Ambiente, v.2, n.3, 2009.

BRASIL Constituição (1988). Constituição da República Federativa do Brasil. Brasília, DF: Senado, 1988.

. Lei n. 12.305, de 2 de Agosto de 2010. Institui a Política Nacional de Resíduos Sólidos; altera a Lei no 9.605 de 12 de fevereiro de 1988; e dá outras providências. Diário Oficial da República Federativa do Brasil. Brasília, DF. 2 de Agosto de 2010a.

Decreto n 7.404 de 23 de Dezembro de 2010. Regulamenta a lei 12305/10, de 2 de agosto de 2010, que institui a Política Nacional de Resíduos Sólidos, cria Comitê Interministerial da Política Nacional de Resíduos Sólidos e o Comitê Orientador para a implantação dos Sistemas de Logística Reversa, e dá outras providências. Diário Oficial da República Federativa do Brasil. Brasília, DF. 23 de Dezembro de 2010b.

Lei 11.445, de 5 de Janeiro de 2007. Estabelece diretrizes nacionais para o saneamento básico; altera as Leis nos 6.766, de 19 de dezembro de 1979, 8.036, de 11 de maio de 1990, 8.666, de 21 de junho de 1993, 8.987, de 13 de fevereiro de 1995; revoga a Lei no 6.528, de 11 de maio de 1978; e dá outras providências. Diário Oficial da República Federativa do Brasil. Brasília, DF. 5 de Janeiro de 2007.

BROLLO, Maria José. Metodologia Automatizada para Seleção de Áreas para Disposição de Resíduos Sólidos. Aplicação na Região Metropolitana de Campinas (SP). 2001. Tese (Doutorado em Saúde Ambiental) - Faculdade de Saúde Pública, University of São Paulo, São Paulo, 2001. Disponível em: <http://www.teses.usp.br/teses/disponiveis/6/6134/tde15042004-134831/>. Acesso em: 2014-12-22.

CARVALHO, André Luciano de; LANZA, Vera Christina Vaz. Orientações básicas para a operação de aterro sanitário. Belo Horizonte: FEAM, 2006.

CEZAR, Layon Carlos. Análise da Comunicação Governamental sobre a Política Nacional de Resíduos Sólidos na Zona da Mata Mineira. 2014. 137 f. Dissertação (Mestrado em Administração). Universidade Federal de Viçosa, Minas Gerais, 2014.

COOPER, Donald R.; SCHINDLER, Pamela S. Métodos de pesquisa em administração. 7 ed. Porto Alegre: Bookman, 2003.

CORDEIRO, Berenice de Souza. Brasil. Lei Nacional de Saneamento Básico:. Ministério das Cidades. Secretaria Nacional de Saneamento Ambiental. Programa de Modernização do Setor Saneamento (PMSS). Brasília: Editora, 2009; v.2. 193p. 
DEMAJOROVIC, Jacques; MIGLIANO, João Ernesto Brasil. Política nacional de resíduos sólidos e suas implicações na cadeia da logística reversa de microcomputadores no Brasil. Gestão \& Regionalidade, v. 29, n. 87, 2013.

FERREIRA, Daniele Araújo; ROSOLEN, Vania. Disposição De Resíduos Sólidos E Qualidade Dos Recursos Hídricos No Município De Uberlândia/Mg. Horizonte Científico, v. 6, n. 1, 2012.

FREIRE, Gerson de Mattos. Análise de Municípios Mineiros quanto à Situação de seus Lixões. 2009, 104f. Dissertação. (Mestrado Análise e Modelagem de Sistemas Ambientais). Programa de Pós-graduação em Análise e Modelagem de Sistemas Ambientais. Departamento de Cartografia e Centro de Sensoriamento Remoto do Instituto de Geociências. Universidade Federal de Minas Gerais. Belo Horizonte, MG, 2009.

Fundação Estadual do Meio Ambiente (FEAM). Panorama da destinação dos resíduos sólidos urbanos no Estado de Minas Gerais em 2012. Belo Horizonte, MG. 2013. Disponível em <http://www.feam.br/images/stories/minas_sem_lixoes/2013/novo/relatrio_de_progresso_ 2012_classificao\%20e\%20panorama\%20rsu.pdf> Acesso em 7 de Junho de 2014.

GIL, Antonio Carlos. Como Elaborar Projetos de Pesquisa. 5ạ ed. São Paulo, Atlas, 2010.

GUARNIERI, Patricia; HASS, Dayana; MONTEIRO, Giovana. A mensuração dos efeitos financeiros e econômicos da logística reversa pela contabilidade ambiental. Revista Meio Ambiente e Sustentabilidade, v. 4, n. 2, p. 202-225, 2013.

GUIMARÃES, Roberto; FONTOURA, Yuna. Desenvolvimento sustentável na Rio+ 20: discursos, avanços, retrocessos e novas perspectivas. Cadernos EBAPE, v. 10, n. 3, p. 508532, 2012.

GUTIERREZ, Rafaela Francisconi; ZANIN, Maria. Empreendimentos econômicos de catadores de resíduos e legislações vigentes: avanços e limites. Gerais: Revista Interinstitucional de Psicologia, v. 4, n. SPE, p. 113-121, 2011.

HOHMANN, Ana Carolina C. Regulação e Saneamento na Lei Federal no 11.445/07. Revista Jurídica da Procuradoria Geral do Estado do Paraná. Curitiba, n. 3, p. 211-244, 2012.

INSTITUTO BRASILEIRO DE GEOGRAFIA E ESTATÍSTICA (IBGE). Pesquisa Nacional de Saneamento Básico: 2008. Rio de Janeiro, 2010. Disponível em:

<http://www.ibge.gov.br/home/estatistica/populacao/condicaodevida/pnsb2008/PNSB_200 8.pdfv> Acesso em 03 Jul. 2014a.

JACOBI, Pedro Roberto; BESEN, Gina Rizpah. Gestão de resíduos sólidos em São Paulo: desafios da sustentabilidade. Estudos Avançados, v. 25, n. 71, p. 135-158, 2011.

JULIATTO, Dante Luiz; CALVO, Milena Juarez; CARDOSO, Thaianna Elpídio. Gestão integrada de resíduos sólidos para instituições públicas de ensino superior. Revista Gestão Universitária na América Latina, v. 4, n. 3, p. 170-193, 2011.

KAWAICHI, Vanessa Mayumi; MIRANDA, Sílvia Helena Galvão de. Políticas Públicas Ambientais: a Experiência dos Países no Uso de Instrumentos Econômicos como Incentivo à 
Melhoria Ambiental. In: XLVI Congresso da Sociedade Brasileira de economia Administração e Sociologia Rural (SOBER). Anais... Rio Branco: Acre, 20 a 23 de julho de 2008.

MILANEZ, Bruno; BUHRS, Ton. Capacidade Ambiental e Emulação de Políticas Públicas: 0 Caso Da Responsabilidade Pós-Consumo para Resíduos de Pilhas e Baterias no Brasil.

Planejamento e Políticas Públicas, no 33. Brasília, DF, 2009.

MILLER JR, G Tyler. Ciência Ambiental. Tradução da $11^{\circ}$ edição norte-americana. 11… ed. São Paulo: Cenage Learning, 2008.

MINISTÉRIO DO MEIO AMBIENTE (MMA). Disponível em: <http://www.mma.gov.br/cidadessustentaveis/residuos-solidos/politica-nacional-de-residuos-solidos> Acesso em 2Agos. 2013.

PROGRAMA MINAS SEM LIXÕES. Disponível em:

<http://www.minassemlixoes.org.br/gestao-municipal/gestao-integrada-de-residuos> Acesso em: 01 Ago. 2013.

REVEILLEAU, Ana Célia. Política Nacional de Resíduos Sólidos: aspectos da responsabilidade dos geradores na cadeia do ciclo da vida do produto. Revista Internacional de Direito e Cidadania, n. 10, p. 163-174, 2011.

SILVA FILHO, Carlos R. V.; SOLER, Fabrício D. Gestão de resíduos sólidos: o que diz a lei. São Paulo: Trevisan, 2012.

SILVA-SÁNCHEZ, Solange S. Política de meio ambiente no Brasil: a construção da cidadania ambiental. Plural (São Paulo. Online), v. 6, p. 20-46, 1999.

SOUZA, Alexandre do Nascimento. Licenciamento ambiental no Brasil sob a perspectiva da modernização ecológica. 2009. Dissertação (Mestrado em Ciência Ambiental) - Ciência Ambiental, Universidade de São Paulo, São Paulo, 2009.

VARELLA, Cinthia Versiani Scott. Revirando o lixo: possibilidades e limites da reciclagem como alternativa de tratamento dos resíduos sólidos. 2011. Dissertação (Mestrado em Engenharia de Produção). Universidade Federal de Minas Gerais, Belo Horizonte: Minas Gerais, 2011. 